EPJ Web of Conferences 110,01040 (2016)

DOI: $10.1051 /$ epjconf/201611001040

(C) Owned by the authors, published by EDP Sciences, 2016

\title{
DISSOCIATION OF NATURAL AND ARTIFICIAL METHANE HYDRATE
}

\author{
S. Y. Misyura ${ }^{1, a}$ \\ ${ }^{1}$ Institute of Thermophysics Siberian Branch, Russian Academy of Sciences, Lavrentiev Ave. 1, Novosibirsk, \\ 630090, Russia
}

\begin{abstract}
Present work deals with natural and artificial methane hydrate dissociation. The heating of the powder produced due to the temperature difference between the external air and the powder. The dissociation rate was determined by gravimetric method. The range of the partial self-preservation for the natural hydrate is significantly longer than for the artificial one and moved to higher temperatures. The destruction of the natural sample is slower than the artificial one. The time-averaged dissociation rate for the artificial sample is equal to $1,25 \% / \mathrm{s}$ and for the natural hydrate corresponds to $0,59 \% / \mathrm{s}$.
\end{abstract}

\section{Introduction}

The use of gas hydrates can be connected both to energy and ecology. The technology of methane hydrate is based on the production, transport and storage. To date, the cost of methane hydrates storage is high because of the need to maintain low temperatures or high pressures. The phenomenon of self-preservation can significantly improve storage efficiency of gas hydrates. The most effective storage is implemented with a maximum low dissociation rate, which provide pellets having a diameter of 7-10 mm [1,2]. Conversely, granules having a diameter of less than $1 \mathrm{~mm}$ lead to high rates of decay and lack of self-preservation.

To date, there is little data on the comparison of artificial and natural gas hydrates dissociation. The dissociation of artificial methane hydrates has been studied in [1-4]. The dynamic method of hydrate generation during the run of the shock wave through the gas bubbles has been investigated in [5-7]. The wall influence on the boiling investigated in [8]. Another method for creating the hydrate [9-13] is a blowing of a liquid nitrogen jet into a vessel with water and creating a shock wave. Gas hydrate formation from the oil-water emulsion was studied in [14]. Present work deals with natural and artificial methane hydrate dissociation.

\section{Experimental data}

The description of the experimental setup and the preparation technique of artificial methane hydrate

a Corresponding author: misyura@itp.nsc.ru 
are given in [1]. The mass concentration of the artificial methane hydrate corresponded to $12.1 \%$ and the natural methane hydrate was $11.5 \%$. Artificial and natural methane hydrate structure corresponded to sI. The formula of the elementary cell is $2 \mathrm{D} \cdot 6 \mathrm{~T} \cdot 46 \mathrm{H}_{2} \mathrm{O}$ (a cell consists of 46 water molecules, two small and six large areas). The average particle diameter of artificial methane hydrate powder corresponded to $1.4 \mathrm{~mm}$ and for the natural methane hydrate was $1.7 \mathrm{~mm}$. The container with the sample was placed on the balance immediately after removing from the liquid nitrogen. The initial temperature of the sample was close to the temperature of liquid nitrogen. The heating of the powder produced due to the temperature difference between the external air and the powder. The dissociation rate was determined by gravimetric method. Fig. 1 shows the rate dependence of the gas hydrates decomposition depending on the time (1 - artificial hydrate; 2 - natural hydrate). Gas hydrate selfpreservation during the breakup is characterized by repeated decrease in the dissociation rate due to the formation of the surface solid ice crust of the pellets. The graphs show that the area of the partial self-preservation for the natural hydrate is significantly longer and moved to higher temperatures. The destruction of the natural sample is slower than the artificial one. The time-averaged dissociation rate for curve 1 is equal to $1,25 \% / \mathrm{s}$ and for the curve 2 corresponds to $0,59 \% / \mathrm{s}$. It is likely that the slower decay of the natural hydrate associated with long period of its creation. As a result, the crystalline structure with significantly lower defectiveness can be formed.

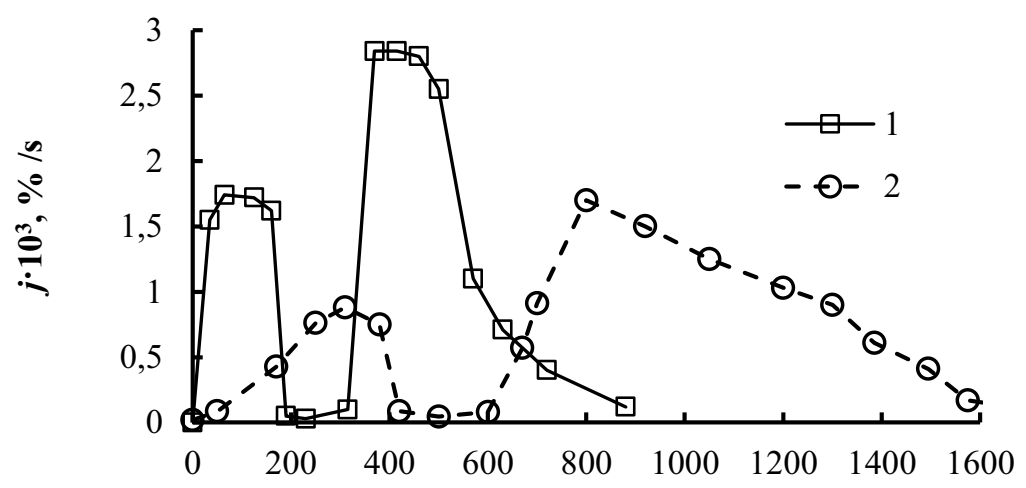

$\boldsymbol{t}, \mathbf{s}$

Figure 1. The rate dependence of the gas hydrates destruction on time: 1 - for the artificial methane hydrate; 2 for the natural methane hydrate.

It is necessary to study the internal crystalline structure of the natural hydrates in further research.

\section{Acknowledgements}

This work was supported by grants of Russian Science Foundation (Project № 15-19-10025).

\section{References}

1. V.E. Nakoryakov, S.Y. Misyura, S.L. Elistratov A.Yu. Manakov, A.E. Shubnikov, J. Engineering Thermophysics, 22 (2), 87 (2013)

2. V.E. Nakoryakov, S.Y. Misyura, Chem. Eng. Sci., 104, 1 (2013)

3. S.Y. Misyura, Chem. Physics Letters., 583, 34 (2013)

4. S.Y. Misyura, V.E. Nakoryakov, Energy and Fuels, 27 (11), 7089 (2013)

5. V.E. Dontsov, A.A. Chernov, E.V. Dontsov, Thermophys. and Aeromech., 14 (1), 23 (2007) 
6. V.E. Dontsov, V.E. Nakoryakov, A.A. Chernov, J. Eng. Thermophys. (1), 1(2009)

7. A.A. Chernov, Int. J. Heat Mass Transfer. 52 (13-14) 3290-3296 (2009).

8. S.Y. Misyura, Wall effect on heat transfer crisis, Exp. Thermal Fluid Sci (2015) Doi:http://dx.doi.org/10.1016/j.expthermflusci.2015.10.002

9. V.E. Dontsov, A.A. Chernov, Int. J. Heat Mass Transfer, 52 (21-22), 4919 (2009)

10. V.E. Nakoryakov, A.N. Tsoi, I.V. Mezentsev, A.V. Meleshkin, J. Engineering Thermophysics, 23 (1), 1 (2014)

11. V.E. Nakoryakov, A.N. Tsoi, I.V. Mezentsev, A.V. Meleshkin, Thermophys. and Aeromech., 21 (3), 279 (2014)

12. V.E. Nakoryakov, A.N. Tsoi, I.V. Mezentsev, A.V. Meleshkin, Thermal Engineering., 61 (13), 919 (2014)

13. V.E. Nakoryakov, A.N. Tsoi, I.V. Mezentsev, A.V. Meleshkin, Izvestiya RAN, Energetika, (3), 61 (2014)

14. A.Yu. Manakov, M.E. Semenov, E.Yu. Shitz, A.S. Stoporev, L.K. Altunina, L.A. Strelets, S.Y. Misyura, V.E. Nakoryakov, J. Thermal Analysis and Calorimetry, (119), 757 (2015) 